
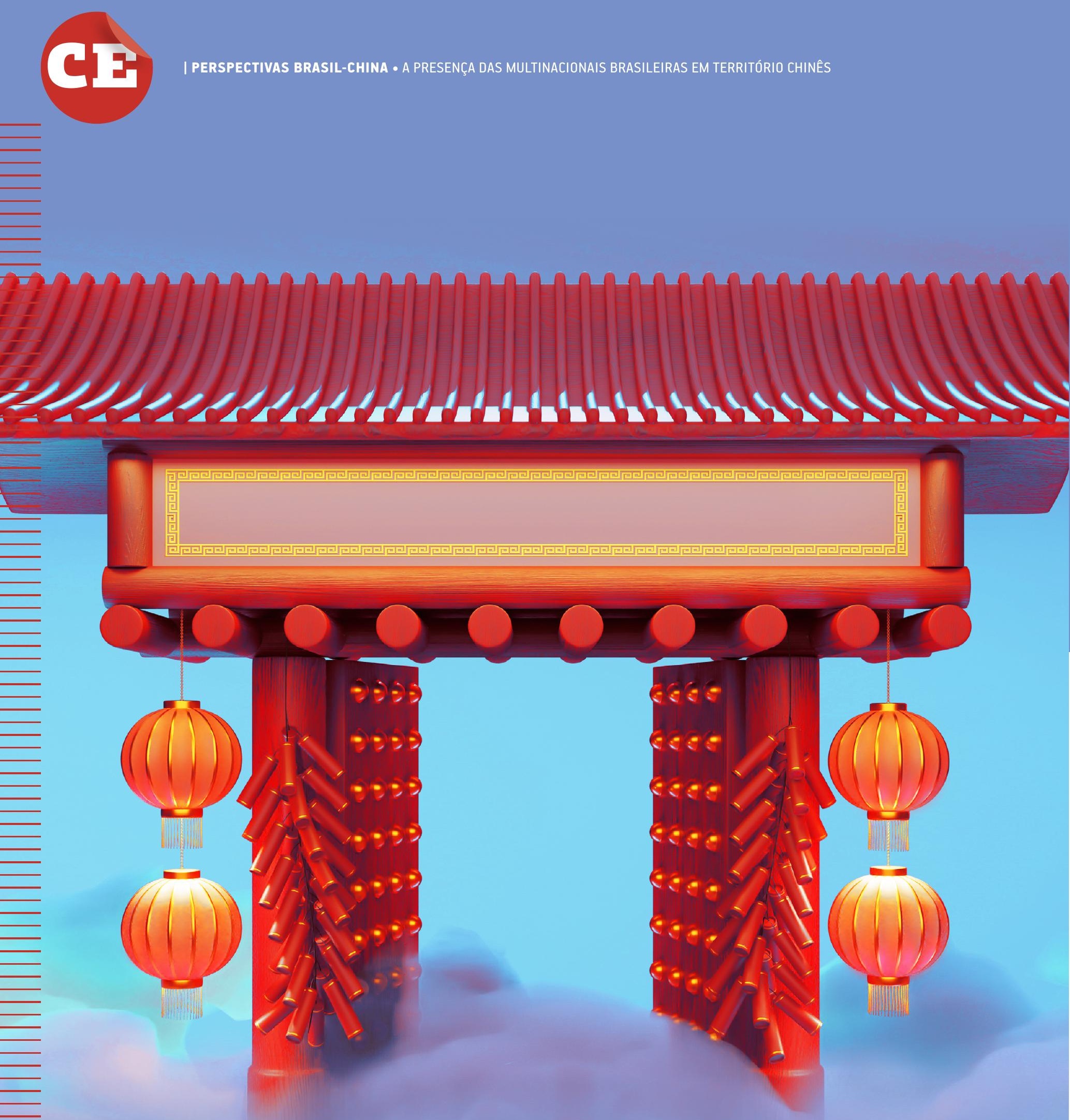


\section{A PRESENÇA DAS MULTINACIONAIS BRASILEIRAS EM TERRITÓRIO CHINÊS}

| POR MARIA TEREZA FLEURY

\section{Em um primeiro estágio, as empresas brasileiras percorreram trajetórias já conhecidas ao se internacionalizarem para a China, mas, em anos recentes, desbravaram novos caminhos.}

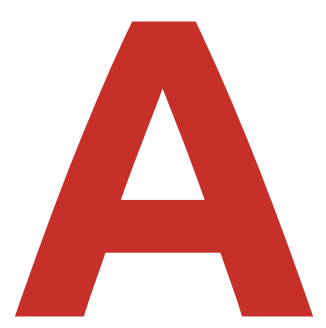

presença do capital chinês no Brasil tem crescido significativamente. Mas, no sentido inverso, como tem sido o movimento de empresas brasileiras para a China? É possível, também, observar crescimento de número de organizações e aprofundamento das operações. Nem a pandemia mudou esse cenário: as empresas brasileiras não só mantiveram suas atividades na China, como, em muitos casos, expandiram-nas.

\section{DESENVOLVIMENTO GRADATIVO}

Desde os anos 2000, temos estudado a trajetória das multinacionais brasileiras, inicialmente pela América Latina, depois rumo aos Estados Unidos, Europa e países asiáticos. Essas empresas configuram-se como um grupo destacado de organizações. Ao se exporem à competição do mercado internacional, desenvolvem novas capacidades, inovam na forma de operação e gestão, desenvolvem formas arrojadas de se relacionar com os clientes e são capazes de lançar novos produtos e serviços. Mais recentemente, realizando pes-

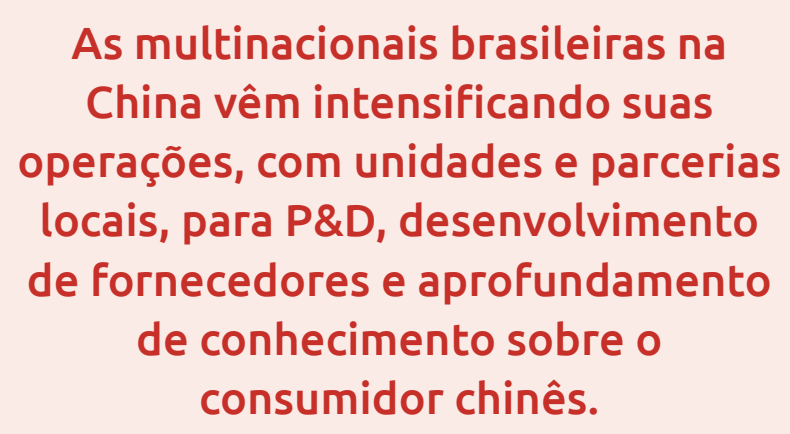

As multinacionais brasileiras na China vêm intensificando suas operações, com unidades e parcerias locais, para P\&D, desenvolvimento de fornecedores e aprofundamento de conhecimento sobre o consumidor chinês.

quisas sobre a inserção de multinacionais na economia digital, observamos como elas se destacam não só no conjunto das empresas brasileiras, mas também entre seus competidores internacionais.

As multinacionais brasileiras que foram para a China têm conseguido, também, colecionar esses atributos. Obviamente, trata-se de um processo gradativo. Foi nos anos 90 que 


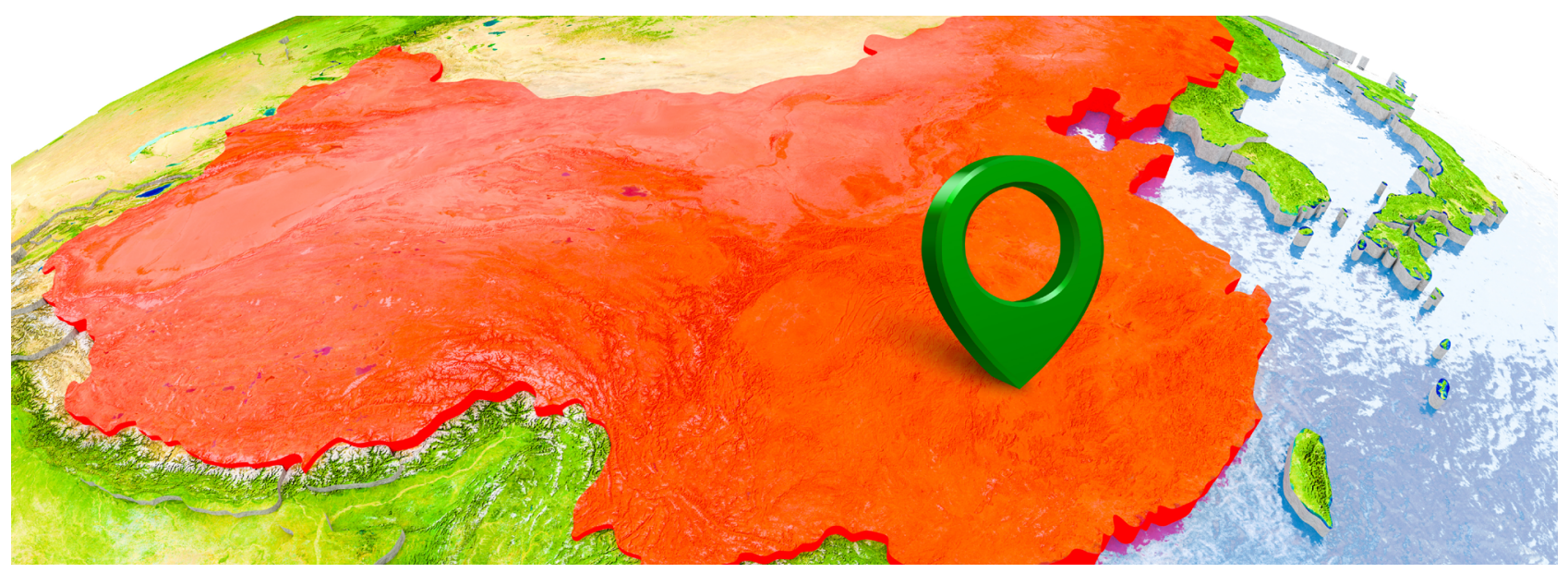

NÚMERO DE MULTINACIONAIS BRASILEIRAS NA CHINA

\begin{tabular}{c|c|c} 
Setor & Número de empresas & Número de subsidiárias \\
\hline Recursos naturais/agronegócio & 4 & 7 \\
\hline Manufatura & 16 & 28 \\
\hline Serviços & 10 & 10 \\
\hline
\end{tabular}

FONTE: FGV CEI (SURVEY DE 2019).

o potencial do mercado chinês e o baixo custo de mão de obra começaram a atrair investimentos internacionais, entre eles o dos brasileiros. A Embraco foi uma das primeiras empresas a se instalar na China, em 1995, com uma operação em Beijing, por meio de joint venture com a Snowflake.

As multinacionais que ali se instalavam tinham que fazê-lo em um regime de equity joint venture com um parceiro chinês. Com o tempo, isso mudou para o regime de contractual joint venture; ou seja, as atividades passaram a ser feitas em subsidiárias próprias, sob controle da matriz. Essas mudanças foram ocorrendo em função de políticas industriais, que definiam quais setores seriam abertos ao capital estrangeiro e quais seriam preservados da concorrência internacional. A preocupação do governo chinês era garantir o spillover tecnológico, em um processo que induzisse a aprendizagem para as empresas locais.

Em alguns casos, houve mudança no perfil de operações, com o gradual aumento da atividade de pesquisa e desenvolvimento nas subsidiárias localizadas na China. Os motivos para isso são diversos, desde a disponibilidade de engenheiros qualificados até a necessidade de conhecer melhor o consumidor chinês. A Embraco, por exemplo, desenvolveu novos modelos de compressores para eliminar o ruí-

\section{Com a pandemia da Covid-19, empresas brasileiras não só mantiveram suas atividades na China, como, em muitos casos, expandiram-nas.}

do das geladeiras que, nas casas chinesas, muitas vezes ficam na sala.

Nos anos 2000, várias empresas brasileiras instalaram-se na China. A Embraer iniciou suas operações em 2000, com um escritório em Beijing e um contrato de joint venture com duas empresas locais, controladas pela gigante estatal China Aviation Industry Corporation. Posteriormente, com a planta de Harbin, a Embraer montou jatos regionais e particulares até a suspensão do contrato, quando das negociações com a Boeing. Com o fracasso dessas negociações, a empresa considera retomar as operações na China. 


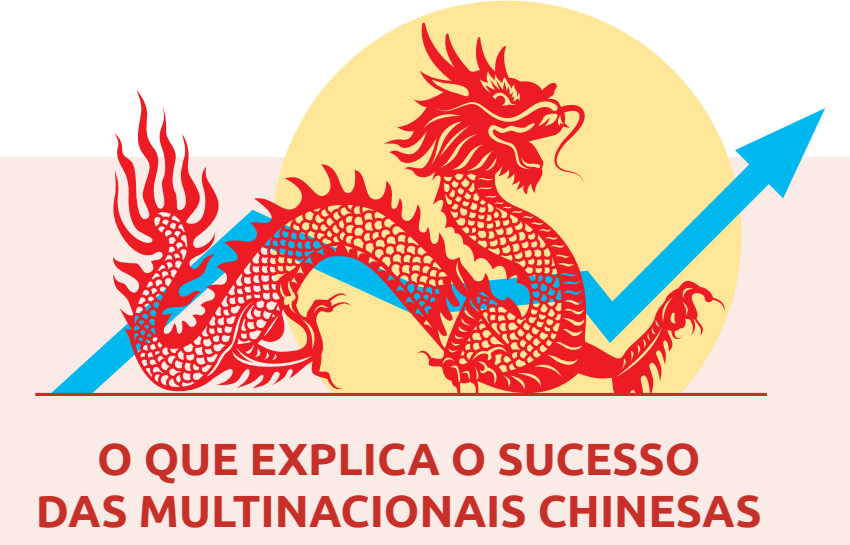

\section{POR TAOTAO CHEN}

A State Grid teve êxito ao investir no Brasil, por unir as competências desenvolvidas na China com a escolha de um mercado preparado para recebê-la.

Como uma empresa da China pode ter sucesso ao investir no exterior? A seguir são apresentados alguns aspectos fundamentais, recolhidos a partir da experiência da State Grid, uma típica empresa estatal chinesa que conseguiu bons resultados no Brasil.

Em primeiro lugar, a companhia do setor elétrico inventou uma tecnologia de destaque, a linha de transmissão de alta tensão, quando a China enfrentou o enorme desafio de transmitir a energia gerada do Oeste para o Leste, em 2004. A tecnologia foi materializada pela construção de mais linhas no país de origem, antes de a empresa se tornar global.

Em segundo lugar, o país destino dos investimentos, o Brasil, tinha um sistema sólido para a seleção de tecnologia a utilizar e contava com um mercado industrial bem estruturado. Com uma janela aberta para receber boas tecnologias, a instituição autorizada pelo governo, a Empresa de Pesquisa Energética (EPE), escolheu, de forma independente, a tecnologia chinesa como a melhor para o mercado brasileiro.

Em terceiro lugar, dadas as grandes diferenças entre a China e o Brasil, a State Grid executou sua estratégia de inserção no mercado brasileiro com sucesso. No início, foi feita a aquisição para aproveitar as vantagens competitivas de uma empresa espanhola já presente no país; em seguida, foi introduzido um sistema operacional avançado que já havia se consolidado no país de origem; além disso, houve disposição para colaborar com provedores locais de Engenharia, Aquisição e Construção (EPC) para contratar talentos brasileiros para cuidar de desafios ambientais complexos.

Em resumo, a State Grid foi exitosa ao ir para fora da China, ao combinar são suas vantagens competitivas desenvolvidas em casa com fatores de negócios sólidos no ambiente dos países investidos.

TAOTAO CHEN > Diretora do Latin American Center of Tsinghua University > chentt@sem.tsinghua.edu.cn

A WEG iniciou suas atividades com a aquisição de uma fábrica em Nantong, produzindo motores elétricos - e, em 2019, já inaugurava sua quarta unidade, voltada para produção de equipamentos de automação industrial. A Vicunha abriu sua primeira subsidiária em Shanghai, em 2005. A Vale estabeleceu joint venture com a empresa chinesa Zhuhai YPM, em 2006, para construção de unidade de peletização; em 2020, anunciou outra joint-venture, com a Ningbo Zhoushan Port, para construir e operar o projeto West III, no porto de Shulanghu, na província de Zhejiang. Em 2009, por meio da subsidiária Kaco, a Sabó, produtora de autopeças, inaugurou a primeira fábrica em Wuxi.

\section{INTENSIFICAÇÃO DAS ATIVIDADES}

Nesta última década, a presença de empresas brasileiras com operações no território chinês aumentou consideravel- mente, em todos os setores - agronegócio, recursos naturais, manufatura e serviços (ver tabela). $\mathrm{O}$ aprendizado intensificou-se, pois as multinacionais do Brasil passaram a atuar em unidades próprias, além de tomar iniciativas para compreender melhor o modo local de fazer negócios e para estudar o consumidor chinês.

A Suzano Papel e Celulose foi um dos destaques no período, ao desenvolver pesquisas conjuntas com parceiros chineses e aprofundar o relacionamento com clientes desse país. Em 2011, a empresa comprou a FuturaGene, pioneira em biotecnologia e produtividade para a indústria florestal, com sede no Reino Unido e laboratórios em Israel, China e Brasil. Após a aquisição, foi feito um acordo para intercâmbio de pesquisa e desenvolvimento com a South China University of Technology, para o uso da celulose do eucalipto nos papéis chineses. A Suzano marcou presença 


\section{A experiência das multinacionais brasileiras na China tem revelado um aprendizado contínuo na forma de operar, com adaptação às políticas governamentais do país, desenvolvimento de novos negócios e produtos e aprimoramento na arte do relacionamento.}

no território chinês por meio da unidade fabril e de escritórios comerciais, procurando ajustar seus negócios a uma característica cultural marcante no país, a valorização da relação direta com fornecedores e clientes.

Essa necessidade de proximidade com os stakeholders levou, também, a Randon, que desde 2001 exportava para a China, a abrir a própria fábrica para produção de lonas e pastilhas de freio para veículos pesados. Em 2020, um ano difícil para as empresas em geral, a Randon anunciou a compra da Nakata, subsidiária da Dana no Brasil, e, assim, dobrou a capacidade de sua fábrica na China.

No setor de varejo, muitas empresas que resolveram investir no mercado chinês precisaram encontrar parceiros que conhecem as particularidades locais ou ajustar sua estratégia conforme foram aprendendo sobre o consumidor do país. A Miolo, por exemplo, participou, em 2011, da feira Wines from Brazil, promovida pela Agência Brasileira de Promoção de Exportações e Investimentos (Apex). Foi nessa ocasião que surgiu o contato com uma importadora chinesa interessada em ser seu representante exclusivo. $\mathrm{O}$ fato de os proprietários dessa empresa parceira terem morado no Brasil ajudou na administração das diferenças culturais e contribuiu para que se desenhasse melhor a empreitada no território chinês. Após a abertura da primeira loja conceito em Shanghai, a companhia vem abrindo novas unidades - e a China já representa o quarto mercado mundial da Miolo. No caso da Arezzo, que também entrou na China em 2011, o aprendizado foi desafiador, desde acertar o gosto do consumidor até definir a faixa de preços a ser praticada. Com a abertura de lojas, propiciando a maior proximidade com o cliente, a empresa foi redefinindo sua estratégia para superar esses desafios.

No setor de serviços, a lógica de investimentos na China não foi diferente. A Stefanini, do segmento de informática, marcou sua entrada no país em 2010, com a aquisição da norte americana Tech Team Global, estabelecendo unida- des em Shanghai e Nanjing. Desde então, a empresa vem expandindo suas operações na China com novas aquisições, para ampliar seu portfólio de serviços. Em 2016, a Stefanini expandiu seus produtos na área de Business Process Outsourcing (BPO), soluções para a indústria automobilística e automação indústria 4.0. Durante 2020, de acordo com a empresa, todos os clientes mantiveram os contratos, um feito, considerando as consequências da pandemia.

Corporações de todos os setores sentiram como o mercado chinês respondeu mais rapidamente, do que os outros, às turbulências causadas pela Covid-19. No segmento de agronegócio, empresas como Marfrig e BRF mantiveram as exportações para a China. A WEG não só reforçou sua participação no mercado chinês, como estreitou, também, o vínculo com os funcionários que trabalham no país, com contatos mais frequentes on-line, o que contribuiu para a troca de conhecimentos e experiências. No caso da Iochpe-Maxion, como a planta fica próxima à cidade Wuhan, onde começou a pandemia, houve um período em que as operações ficaram paradas, mas logo a produção foi retomada e hoje está acima dos volumes pré-Covid.

A experiência das empresas brasileiras com operações na China tem revelado um aprendizado contínuo na forma de operar, com adaptação às políticas governamentais do país, desenvolvimento de novos negócios e produtos e aprimoramento na arte do relacionamento. Esse ganho de experiência tem se refletido, inclusive, na repatriação de conhecimento, propiciando maior competitividade a essas organizações.

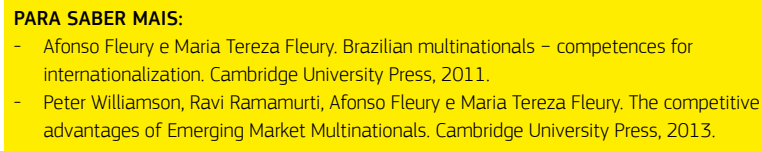

MARIA TEREZA FLEURY > Professora da FGV EAESP > mtereza.fleury@fgv.br 